\title{
EFECTO DE LA PODA FITOSANITARIA SOBRE LA ENFERMEDAD ESCOBA DE BRUJA EN EL CULTIVO DE CACAO
}

\author{
THE PHYTOSANITARY PRUNING EFFECT ON THE WITCHES' BROOM DISEASE IN THE \\ COCOA FARMING
}

\author{
Rubén Darío Rivera-Fernández, Oswaldo Valarezo-Beltron, Leonardo Vera-Macías, \\ Jesús Enrique Chavarría-Párraga y Ángel Monserrate Guzmán-Cedeño
}

\begin{abstract}
RESUMEN
La enfermedad escoba de bruja es el principal problema fitosanitario del cacao y su manejo está en función de la poda fitosanitaria, sin embargo, su eficiencia está supeditada al tiempo de aplicación. El objetivo del presente estudio fue establecer el momento adecuado para realizar la poda en la estación de verano. Se estudió la poda fitosanitaria en dos meses dentro de la estación de verano. La primera en el mes de agosto (1-15) y la segunda en diciembre (1-15). Como material experimental se utilizaron los Clones de cacao 575 y 576 de 15 años de edad con una densidad de siembra de 1111 pl.ha ${ }^{-1}$. Se identificó el ciclo biológico de Moniliophthora perniciosa registrando: inoculación, incubación e infección, tomando como tiempo los días de cada etapa. Además, después de la poda fitosanitaria se contaron las infecciones tanto en brotes, cojinetes y mazorcas, y con ello se obtuvo el promedio del número de infecciones por árbol. Entre el 10 y 15 de enero se inició la esporulación del

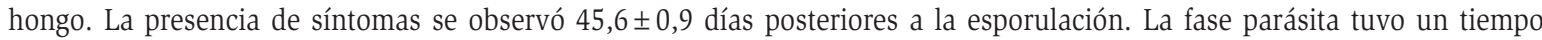
de 39,4 $\pm 9,22$ y la necrosis total fue de 10,11 \pm 3 ,4 días. Después de realizada la poda fitosanitaria en agosto se presentaron nuevas formaciones de $M$. perniciosa, las mismas que estuvieron en capacidad de formar basidiocarpos en la estación invernal subsiguiente. Por el contrario, al podar en diciembre no se cuenta con hongos con capacidad de formar basidiocarpos. Las evidencias muestran la influencia de la poda fitosanitaria realizada en diciembre sobre el ciclo biológico de M. perniciosa y los niveles de infestación en el cacao.
\end{abstract}

PALABRAS CLAVE: epidemiologia, infecciones, síntomas, biología, escoba de bruja

\begin{abstract}
The witches' broom disease in the main phytosanitary problem of cocoa and its management is a function of pod removal, however, their efficiency is subject to application time. The aim was to establish the right time in summer season. Pruning the plant was studied in two months in the summer season. The first in August (1-15) and the second in December (1-15). Clones 575 and 576 of 15 years cocoa with a planting density of 1111 pl.ha $^{-1}$ was used as experimental material. The life cycle of Moniliophthora perniciosa was identified: inoculation, incubation and infection, taken the time in days for each stage. Furthermore, after the pruning infections, bearings and ears were counted, and thus the average number of infections per tree was obtained. Between 10 and 15 January sporulation of the fungus starts. The presence of symptoms was observed 45,6 \pm 0,9 days after sporulation. The parasitic phase was 39,4 $\pm 9,22$ days and total necrosis was $10,11 \pm 3,4$ days. After the phytosanitary pruning in August, new formations of $M$. perniciosa were able to form basidiocarps in subsequent winter season. In December the fungus were not capable of forming basidiocarps. The evidence shows the influence of plant pruning in December on the biological cycle of $M$. perniciosa and infestation levels of cocoa.
\end{abstract}

KEYWORDS: epidemiology, infection, symptoms, biology, witches broom 


\section{INTRODUCCIÓN}

Se conocen más de 30 enfermedades que atacan al cultivo de cacao, en su mayoría causadas por hongos; pero pocas producen daños que representen pérdidas económicas considerables. Las enfermedades del cacao presentan serios problemas para su control por la baja respuesta a los fungicidas, lo que se agrava cuando se trata del manejo de plantaciones con certificación orgánica (INIAP, 2008).

Desde su reporte como enfermedad, la escoba de bruja cuyo agente causal es Moniliophthora perniciosa, ha sido la más importante económicamente del cacao. En Surinam, por ejemplo, redujo la producción a la mitad tan solo en cinco años (Wardlaw, 1929). En Ecuador, de 900,000 quintales en promedio entre los años 19141917, para el año 1926 disminuyó a 300,000 quintales (Garcés, 1946).

Lo descrito en las primeras investigaciones sobre el ciclo biológico no ha tenido cambios considerables, por tal motivo algunas de las referencias citadas obedecen a inicios de las investigaciones sobre el tema. Durante el invierno las esporas son transportadas por el viento, llegan al tejido meristemático de la planta y en un tiempo corto (30 minutos) se produce la germinación en presencia de agua 0 alta humedad atmosférica (Briton y Cheesmam, 1931). La incubación inicia con la penetración al tejido y su consecuente degradación a causa de hifas en forma de punta que se introducen por los estomas de hoja de la planta (Kilaru y Hasenstein, 2005). La infección se identifica con la aparición de los síntomas que en condiciones de campo dependen en gran parte de las condiciones del cultivo, principalmente de la tasa de crecimiento de los nuevos brotes (Briton y Cheesmam, 1931). Los síntomas son visibles en brotes, flores o mazorcas con claras hipertrofia. Baker y Mckee (1943) encontraron la presencia de síntomas entre tres y cinco semanas después de la inoculación, al igual que Scarpari et al. (2005) en inoculaciones artificiales. Es necesario el estudio de la infección en diferentes condiciones climáticas donde se desarrolla el cultivo. En su estado saprófito forman sus esporóforos hasta por 18 meses (Stell, 1938). De Verteuil (1932) menciona un periodo entre 640 y 660 días. El estado saprofito puede formarse en tres semanas y se requieren 14 semanas para producir esporóforos (Stell, 1932). Marelli et al. (2009) registraron 20 y 270 días para dichas etapas, respectivamente.
Entre los principales métodos de control esta la poda. No existen dudas que la poda reduce considerablemente la infección de la enfermedad. Tomando en cuenta el método y el tiempo de aplicación (Stell, 1929), al parecer la poda no ha sido del todo eficiente ya que se observa alto niveles de infestación en las fincas productoras. Por otro lado, al contar con pocos estudios locales sobre el efecto de las podas en épocas secas no ha establecido el momento más óptimo para realizar la poda fitosanitaria, la cual está determinada exclusivamente para la eliminación de tejido enfermo. En muchos casos, en zonas del litoral ecuatoriano se recomienda realizar la poda fitosanitaria simultáneamente con la poda de mantenimiento. Esta última tiene como objetivo eliminar tejido sano o infestado de manera que el árbol mantenga una arquitectura adecuada para el ingreso del aire y la luz solar y su realización debe ser antes del inicio de las lluvias (Suarez, 1996). Sin embargo, se ha observado la presencia de escobas de bruja después de estas prácticas lo que aumenta la infestación cada año, a pesar de contar con períodos prolongados de sequía que hace que la intensidad de infección disminuya (INIAP, 1987). El manejo adecuado de la poda fitosanitaria y su época de realización puede reducir considerablemente la infestación, particularmente cuando se tiene dos estaciones climáticas bien definidas, tomando en cuenta los tiempos de las etapas del ciclo biológico del hongo. Con los antecedentes antes expuestos se plantea como objetivo establecer el momento adecuado, dentro del periodo de la estación de verano, para realizar la poda fitosanitaria que disminuya los niveles de escoba de bruja en el cultivo de cacao.

\section{MATERIALES Y MÉTODOS}

El experimento se realizó por dos años consecutivos entre junio 2011 y mayo de 2013, en el banco de germoplasma de cacao ubicado en el campus politécnico El Limón de la Escuela Superior Politécnica Agropecuaria de Manabí, ubicado en la ciudad de Calceta, cabecera cantonal de Bolívar provincia de Manabí Ecuador por dos años consecutivos correspondientes entre junio de $2011 \mathrm{y}$ mayo de 2013. Geográficamente se ubica a $0^{\circ} 49^{\prime 2} 23^{\prime \prime}$ de Latitud Sur y $80^{\circ} 11$ "01" de Longitud Oeste. Entre las características climáticas se tiene una precipitación de $838.7 \mathrm{~mm}$ anuales concentradas entre los meses de enero y abril (aunque en ciertas ocasiones inician en el mes de diciembre), $25,6{ }^{\circ} \mathrm{C}$ de temperatura media y 78 $\%$ de humedad relativa. 
Se utilizó como material experimental clones de cacao 575 y 576 , los mismos que son recomendados para el valle del Carrizal (INIAP, 2008). Los clones están establecidos en el banco de germoplasma de la Escuela Superior Politécnica Agropecuaria de Manabí Manuel Félix López (ESPAM MFL) que está constituido por 12 accesiones. Cada clon en estudio estuvo divido en dos parcelas de 25 plantas.

Previo al establecimiento del experimento, se realizaron prácticas de manejo del cultivo como poda de mantenimiento y fitosanitaria, riego y fertilización. La poda de mantenimiento se realizó entre mayo y junio teniendo en cuenta que haya terminado la cosecha. La poda fitosanitaria se realizó en dos períodos diferentes en función del experimento siendo la primera en julio y agosto y la segunda en las primeras semanas de diciembre. El riego fue suministrado mediante riego de microaspersión (subfoliar) en función de las condiciones ambientales y los reportes de la evaporación registrada en la estación meteorológica de la ESPAM MFL. La fertilización fue a base de Nitrógeno (Urea), Fosforo (Superfosfato triple) y Potasio (Muriato de potasio). Se homogenizó un mezcla de 1:1:1 y se aplicó 100 g.planta ${ }^{-1} \cdot a_{n} 0^{-1}$. Paralelamente se realizaron controles de malezas tres veces al año.

Para la identificación del ciclo biológico, se retiraron las escobas de bruja suspendidas en los árboles en el área en estudio. Para asegurar el inóculo en condiciones de campo, se contó con una parcela de 25 plantas (dentro del banco de germoplasma) sin realizar podas de mantenimiento y fitosanitario, simulando condiciones adecuadas para el desarrollo del hongo y así asegurar la esporulación en la estación invernal que permitiera la inoculación natural y posterior seguimiento del ciclo de la enfermedad. También se realizó un seguimiento de las precipitaciones apoyados de la estación meteorología de la ESPAM MFL.

Inoculación. Se estableció cuando ocurrió la presencia de los primeros basidiocarpos. Para determinar este momento se realizaron observaciones diarias en los tejidos necróticos por escobas de bruja en el lote de producción de inóculo. Estas observaciones se iniciaron a partir de las primeras lluvias.

Incubación. Para esta variable se consideró el tiempo (en días) que trascurrió desde la inoculación hasta la aparición de los primeros síntomas. Para ello, se realizaron observaciones en los lotes en que previamente se eliminaron la totalidad de los tejidos infectados con escoba de bruja, para asegurar que el nuevo tejido infestado sería provocado por la inoculación identificada en el lote en estudio.

Duración del período de infección. Una vez que se presentaron los síntomas tanto en brotes, flores y fruto, se procedió a identificarlas con cinta de colores lo que facilitaba la contabilidad de los días que presentaba cada escoba. Se tomaron los días de duración de las escobas en estado parasito (escobas verdes) y el tiempo de la necrosis. Para las escobas verdes se consideró el tiempo en días desde la aparición de los síntomas hasta el inicio de la necrosis. La necrosis o etapa saprofita se consideró el tiempo en días desde el inicio de la necrosis hasta que la totalidad del tejido estuvo necrótico.

Se establecieron dos momentos para realizar la poda fitosanitaria dentro del periodo de la estación de verano. El primero fue realizado en agosto (entre $1 \mathrm{y}$ 15) y el segundo en diciembre (entre 1 y 15). La poda fitosanitaria consistió en eliminar la totalidad de los tejidos infectados provocados por la escoba de bruja. Una vez realizada la poda, cada mes se registraban las infecciones tanto en brotes, cojinetes y mazorcas, y con ello se obtenía el promedio del número de infecciones por árbol. De las parcelas de 25 árboles se tomaron cinco arboles al azar como unidad de muestreo y de allí en adelante, los datos se tomaron en los mismos árboles.

\section{RESULTADOS Y DISCUSIÓN}

\section{Identificación del ciclo biológico}

Inoculación. Las primeras proliferaciones de esporas se presentaron después de $14 \pm 1,58$ días de precipitación continua y mayores a $5 \mathrm{~mm}$ diarios, coincidiendo en los dos años consecutivos de evaluación (Figura 1). Los basidiocarpos en escobas de bruja con prolongado tiempo de sequía, al parecer, necesitan este tiempo para reactivarse y formar sus órganos reproductores. Una vez aparecen las primeras formaciones las siguientes semanas fue continua la presencia de basidiocarpos en condiciones climáticas favorables como precipitaciones y humedad relativa que entre enero y abril son muy frecuentes en esta zona. Es probable que para el caso de escobas de bruja con menor tiempo en estado saprofito no necesiten el mismo tiempo observado en esta investigación. 


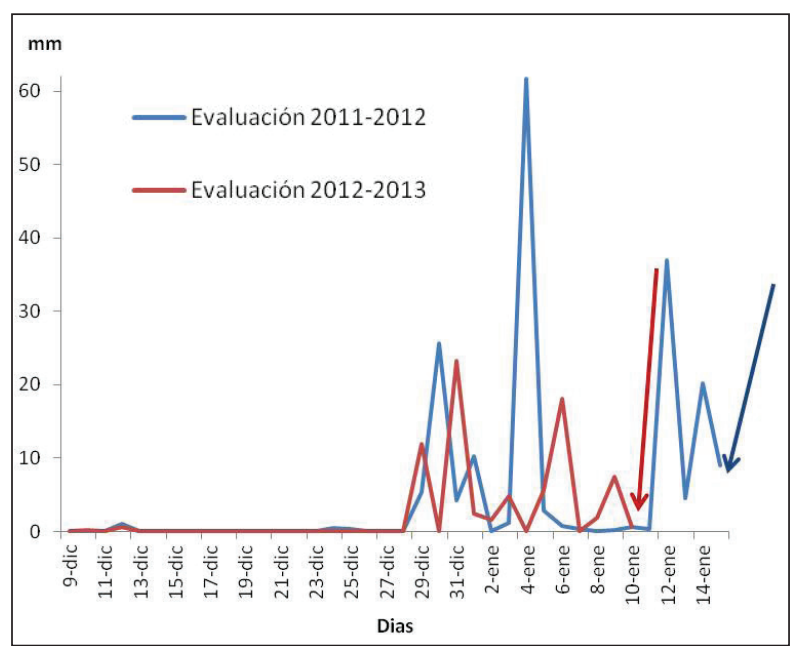

Figura 1. Tiempo de la formación de los basidiocarpos en condiciones de campo (las fechas indican el tiempo de esporulación).

Es necesario mencionar que dada las condiciones climáticas y el ciclo biológico del hongo, en las condiciones del valle del Carrizal solo se producen basidiocarpos en escobas de bruja, formadas en años anteriores (Garcés, 1946). La identificación del momento de formación de basidiocarpos podría sugerir los límites para realizar la poda fitosanitaria, si bien es cierto que las condiciones climáticas podrían variar de un año a otro, si se cuenta con datos meteorológicos periódicos, se puede estimar el tiempo límite de la poda fitosanitaria sin que esta contribuya a la proliferación del hongo, que para este caso en particular, sería antes del 10 de enero (Figura 1).

En la figura 2, se aprecian las primeras producciones de basidiocarpos a nivel de campo. En los arboles los tejidos necróticos son muy visibles, pero no así los basidiocarpos, por tal razón se necesita ser minucioso para identificar las formaciones, sobre todo las iniciales que puede pasar desapercibidas en ciertos casos. Por el contario, es muy fácil identificar a los basidiocarpos una vez que han liberado las esporas, y presentan el característico color blanco cremoso de fácil visibilidad.
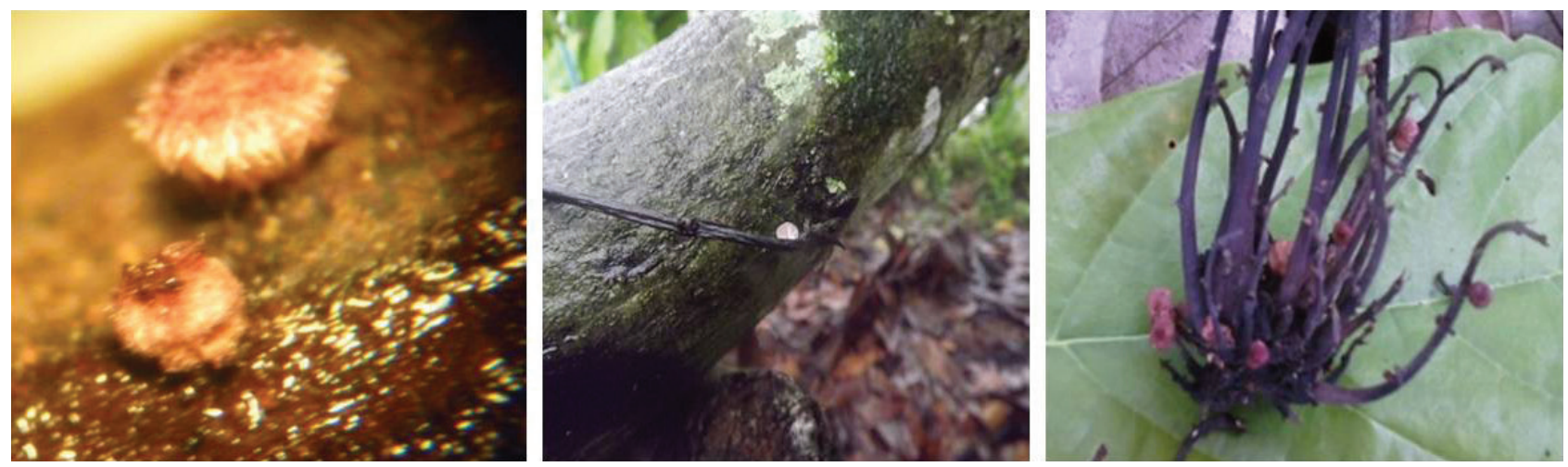

Figura 2. Presencia de basidiocarpos a nivel de campo.

Los primeros basidiocarpos se encontraron en yemas axilares, inicialmente el píleo presenta un color blanco cremoso para después tener una apariencia más rosada, el tallo puede variar levemente de longitud y cuando ha liberado las esporas se torna oscuro. Durante la

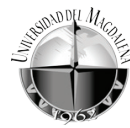
estado saprófito, se pudo observar que no es necesario que la totalidad de la escoba de bruja esté necrótica para poder formar basidiocarpos, ya que en ciertos casos estos se formaron en pequeñas partes necrosadas, aunque gran parte de la lesión estaba en este proceso.
Otra característica fue que a pesar de la disposición de la escoba de bruja en el árbol y las continuas precipitaciones, existían tejidos necrosados sin humedecerse, lo que es un factor influyente al momento de formar los basidiocarpos, puesto que se necesita humedad para la formación de los mismos. Esta característica se presentó en diferentes tejidos infectados (Figura 3). Tiene como particularidad un color blanquecino que podía recubrir total o parcialmente el tejido que probablemente este asociado a microorganismos antagonistas. Blakeman y Fokkema (1982) mencionan que es posible encontrar microorganismos del medio con 
notable actividad antagónica, entre ellos los ascomicetes. (Macagnan et al., 2006)

Presencia de síntomas.- Los primeros síntomas de escobas de bruja se observaron $45.16 \pm 0,9$ días después de la emisión de los primeros basidiocarpos, tanto en brotes axilares, como en cojinetes florales y mazorcas (Figura 4). El tiempo del estado parásito (escobas verdes) en un 57,38 \% tuvo una duración entre 30 y 45 días, tomando como punto final el inicio de la necrosis. Sin embargo, se registraron duraciones de 60 días, relacionadas con factores propios del tejido infectado, como el tipo de tejido ya que no tiene el mismo tiempo un brote axilar que un cojinete floral e incluso en un mismo tejido, si el tamaño difiere considerablemente el tiempo podría variar. Respecto al tamaño es posible que esté relacionado con la necesidad de tener una mayor ruptura de los Blisters que según Dabydeen y
Sreenivasan (1989) es el mecanismo de la necrosis en el tejido. Otro factor observado fue la influencia de agentes patógenos y saprófitos relacionados a la escoba de bruja que aceleran el proceso de descomposión. El tiempo en la etapa saprófita obtuvo en promedio 10,11 días $\pm 3,4$. El 55,2\% estuvo entre 5 y 15 días tomados desde los primeros sintomas de necrosis hasta la necrosis total del tejido (Tabla 2). Berchimol et al. (2001) encontraron entre 34,9 y 65,2 días para el estado parásito (escobas verdes) y entre 6 y 10 días para la necrosis (escobas secas) bajo las condiciones de la microrregión de Belen-Brazil. En condiciones de laboratorio, Marelli et al. (2009) registraron 30 días después de la infección paraa la presencia de síntomas, 80 días para el inicio de la necrosis y 100 días para la necrosis total. Por su lado, Scarpari et al. (2005) encontraron 21 a 35, 21 a 61 y 61 a 132 días para la presencia de síntomas, estado parásito e inicio y final de la necrosis, respectivamente.
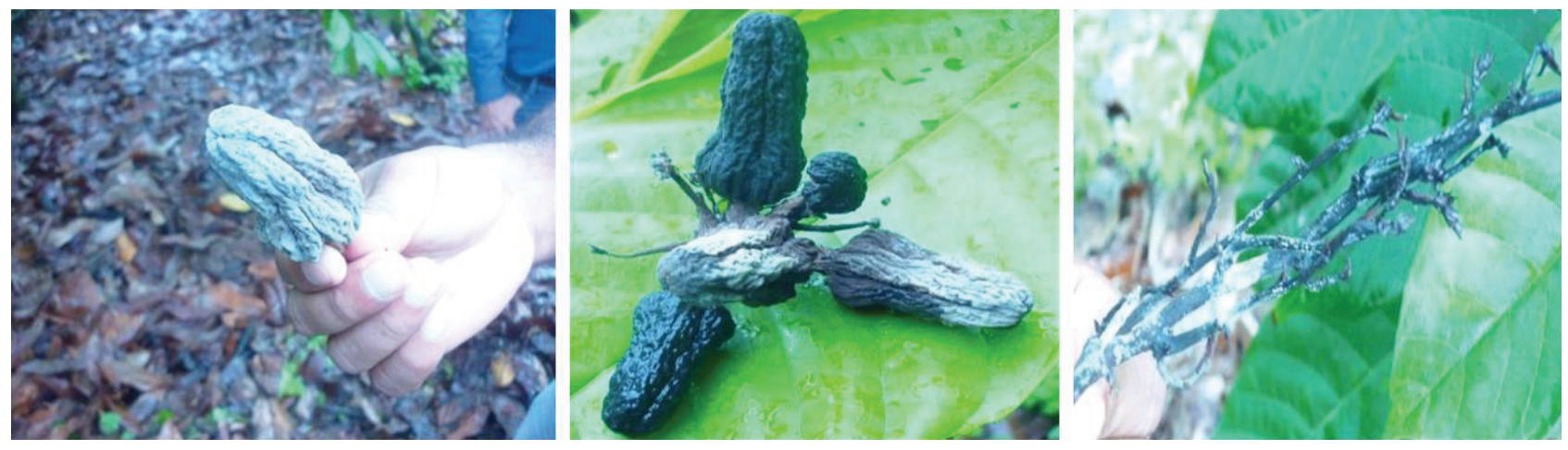

Figura 3. Película blanquecina presente en tejidos infectados de Moniliophthora perniciosa
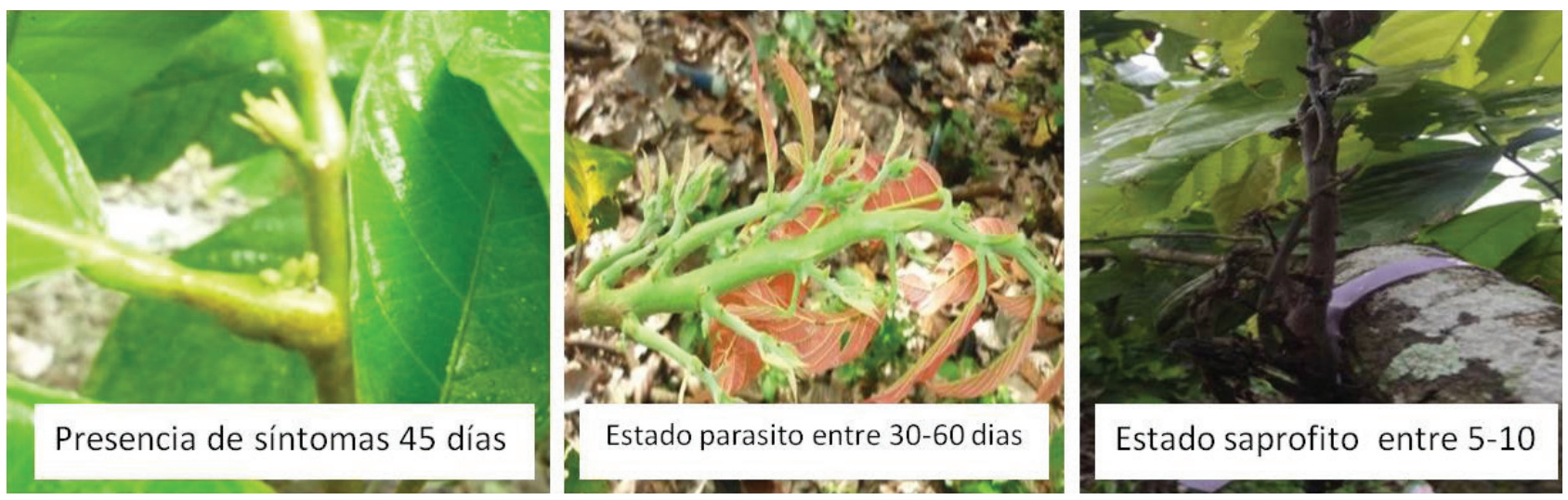

Figura 4. Estados de la enfermedad escoba de bruja en condiciones de campo. a) Presencia de síntomas a los 45 días b) Estado parásito entre 30-60 días c) Estado saprofito entre 5 y 10 días 
Tabla 1. Número de escobas por árbol antes la poda fitosanitaria

\begin{tabular}{|c|c|c|c|c|c|c|c|}
\hline \multirow{2}{*}{ Clon } & \multicolumn{3}{|c|}{ Escobas Verdes } & \multicolumn{3}{|c|}{ Escobas secas } & \multirow{2}{*}{ Tota } \\
\hline & Cojinete & Brotes & Mazorcas & Cojinete & Brotes & Mazorcas & \\
\hline \multicolumn{8}{|l|}{2011} \\
\hline 575 & 3 & 27 & 1 & 0 & 45 & 1 & 77 \\
\hline 576 & 9 & 24 & 1 & 0 & 23 & 1 & 58 \\
\hline \multicolumn{8}{|l|}{2012} \\
\hline 575 & 3 & 15 & 0 & 1 & 30 & 1 & 60 \\
\hline 576 & 4 & 20 & 2 & 0 & 25 & 1 & 51 \\
\hline
\end{tabular}

Tabla 2. Tiempo (días) de las etapas del ciclo biológico de Moniliophtora perniciosa

\begin{tabular}{lc}
\hline \multicolumn{1}{c}{ Parámetros } & Media (días) \\
\hline Incubación & $45,16 \pm 0,9$ \\
$\begin{array}{l}\text { Duración del estado parasito } \\
\text { (escobas verdes) }\end{array}$ & $39,4 \pm 9,22$ \\
$\begin{array}{l}\text { Duración del estado saprofito } \\
\text { (escobas necróticas) }\end{array}$ & $10,11 \pm 3,4$ \\
\hline
\end{tabular}

\section{La poda fitosanitaria}

Durante la poda fitosanitaria se registró en promedio entre 77 y 58 (2011) y 60 y 51 (2012) infecciones de escoba de bruja de los Clones 575 y 576, respectivamente, siendo más evidentes en los brotes axilares y apicales (Tabla 1). Las escobas de bruja verdes parecen ser de nuevas infecciones y las saprofitas de la acumulación de años anteriores. Según van Hall y Drost (1907) la supresión de todos los órganos infectados era la medida adecuada para la erradicación de la enfermedad, además que en casos donde era muy alta la infección (como en el presente caso) se debería realizar la supresión en masa, eliminando toda la copa del árbol. Rorer (1913) cuestionó la eficiencia de la poda o la eliminación de nuevas escobas, sugiriendo que a pesar de realizar esta práctica se mantienen los problemas de escoba de bruja. Por otro lado, no existen posibilidades de que la poda fitosanitaria modifique la manera de infección o los tiempos de necrosis o cualquier otra función fisiológica del hongo. Lo que se espera con la poda fitosanitaria realizada en diciembre es coincidir con las condiciones climáticas favorables para el desarrollo del hongo.

Después de la poda realizada en agosto se observan nuevas infecciones de escoba de bruja, teniendo en promedio $15 \pm 2,7$ y 16,3 $\pm 2,2$ de escobas verdes para los años 2011 y 2012, respectivamente. En el caso de la poda en diciembre se alcanzó $10 \pm 3,4$ y $11 \pm 2,5$ escobas verdes para los mismos años (Tabla 3). En lo concerniente a escobas necróticas por árbol, solamente se tuvo presencia en la poda de agosto, todas con capacidad para formar basidiocarpos, y de los cuales más del 50 \% formaron esporóforos. Las escobas necróticas fueron formadas después de la poda realizada en agosto y tuvieron suficiente tiempo para pasar de parásito a saprófita antes de la estación lluviosa. Puesto que entre septiembre y diciembre no existen inóculos, es posible que sean producidas por esporas latentes que permanecieron en la planta.

Tabla 3. Influencia de la poda fitosanitaria en la presencia de Moniliophtora perniciosa

\begin{tabular}{lcccc}
\hline \multirow{2}{*}{ Parámetros } & \multicolumn{4}{c}{ Poda fitosanitaria } \\
\cline { 2 - 5 } & \multicolumn{2}{c}{ agosto } & \multicolumn{2}{c}{ diciembre } \\
\cline { 2 - 5 } & $\mathbf{2 0 1 1}$ & $\mathbf{2 0 1 2}$ & $\mathbf{2 0 1 1}$ & $\mathbf{2 0 1 2}$ \\
\hline $\begin{array}{l}\text { Número de escobas } \\
\text { verdes por árbol }\end{array}$ & $15 \pm 2,7$ & $16,3 \pm 2$ & $10 \pm 3,4$ & $11 \pm 2,5$ \\
$\begin{array}{l}\text { Número de escobas } \\
\text { necróticas por árbol }\end{array}$ & $4 \pm 1,3$ & $5 \pm 2,4$ & 0 & 0 \\
$\begin{array}{l}\text { Porcentaje de } \\
\text { escobas que } \\
\text { formaron esporóforos }\end{array}$ & $52 \%$ & $55 \%$ & 0 & 0 \\
\hline
\end{tabular}


Si se considera el número de plantas en el lote, se tendría una cantidad muy alta de escobas de bruja. Stell (1932) menciona que una escoba de bruja puede producir 100 esporóforos, cada uno de ellos con capacidad de producir entre 20 y 30 millones de esporas. Por tal motivo, el principal objetivo de la poda fitosanitaria es lograr que no se formen los esporóforos, lo cual fue evidente en la poda fitosanitaria realizada en diciembre.

Al podar en diciembre se eliminaron las escobas de bruja que se formaron entre septiembre y diciembre y observadas en la poda de agosto. Al no tener tejido infectado, no se pudo observar formaciones de basiocarpos dentro de la parcela correspondiente a la poda realizada en diciembre, al contrario de la realizada en agosto cuando se encontraron formaciones de basiocarpos dentro de la parcela. El efecto del momento de realizar la poda fitosanitaria, se puede interpretar como una ruptura del ciclo biológico de la escoba de bruja. Este efecto se puede verificar por el hecho de que la estación lluviosa tuvo ausencia total de basidiocarpos (Figura 5). Por el contrario, al podar en agosto solo se eliminaron las escobas que se formaron en la estación invernal. Se observó que las escobas formadas en la estación lluviosa no formaron basidiocarpos en la misma estación en la cual se iniciaron con lo que se plantea eliminarlas antes de la siguiente estación invernal.

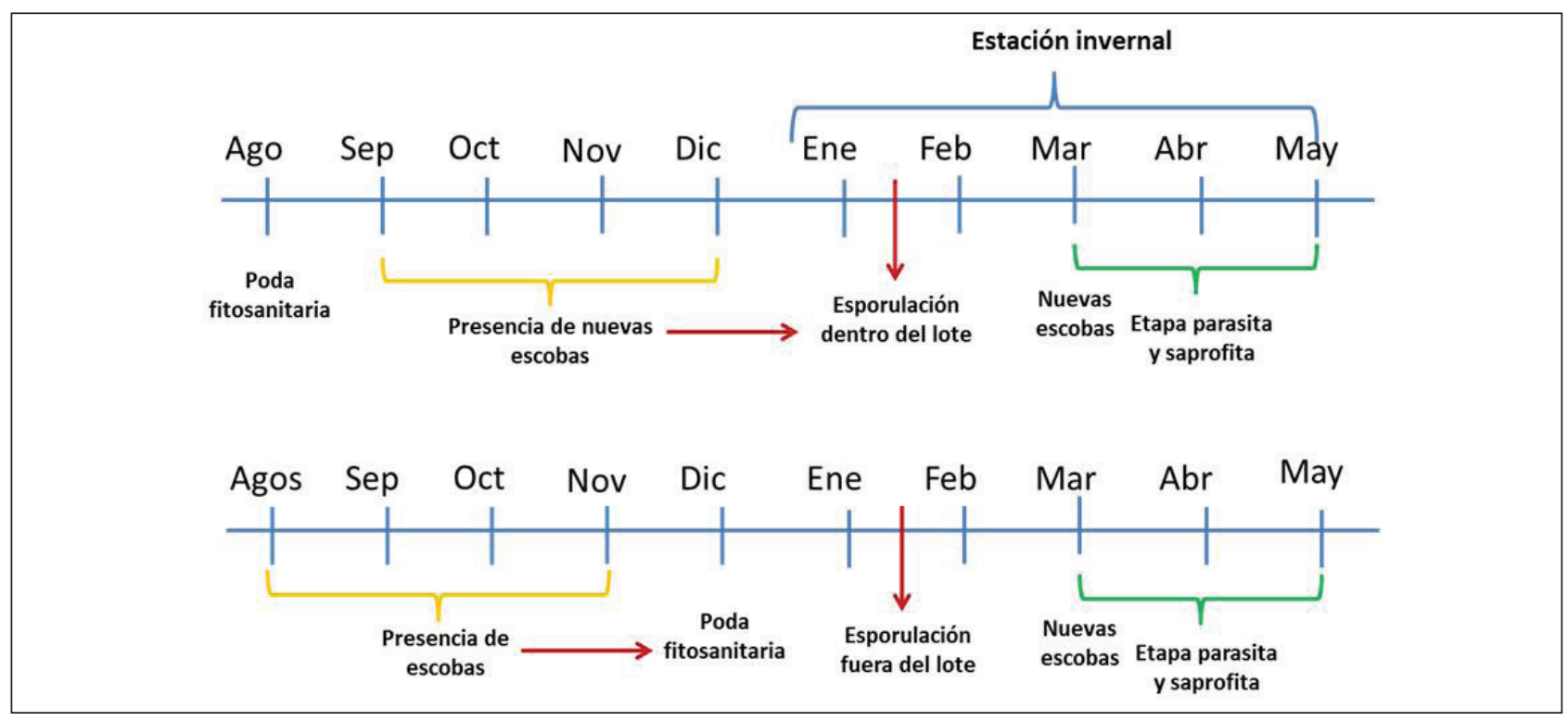

Figura 5. Ciclo biológico de la enfermedad escoba de bruja bajo las condiciones ambientales del valle Carrizal en dos momentos de la poda fitosanitaria dentro del periodo de la estación de verano.

Bajo las condiciones ambientales del valle del Carrizal, a partir de la segunda quincena de enero se formaron los basidiocarpos, y en marzo se presentaron síntomas en yemas, flores y fruto alcanzando máximo en mayo su etapa saprófita para aquellas formaciones iniciales. Es necesario aclarar que la formación de escobas de brujas fue durante todo el año, en menor o mayor proporción, y en este documento se evalúan las primeras escobas formadas, por lo cual para los meses subsiguientes se debe considerar la amplitud del tiempo planteado.

Hay que considerar el hecho que las fincas productoras en muchos casos están cercanas y podría existir la contaminación desde fuera del lote, así como la posibilidad de que al momento de la eliminación de las escobas de bruja no se realice eficientemente.

\section{CONCLUSIONES}

La época de realización de la poda fitosanitaria influye sobre la enfermedad escoba de bruja, siendo la poda de diciembre determinante para disminuir los niveles de la enfermedad, ya que al tener una estación invernal definida se logra escapar de las condiciones adecuadas para el desarrollo de M. perniciosa, provocando una ruptura de su ciclo biológico. 


\section{BIBLIOGRAFÍA}

Baker, R. y R. Mckee. 1943. Witches broom disease investigations VI. The infection of flower cushions and pods of cacao by Marasmius perniciosus Stahel. Tropical Agriculture 20: 188-194.

Berchimol, R., R. Carmeira y R. Muniz. 2001. Aspectos epidemiológicos da vassoura-de-bruxa do cupuacuzeiro na microrregiao de Belen. Pesquisa Agropecuaria Brasileira 36(2): 279-283.

Blakeman, J. y N. Fokkema. 1982. Potencial for biological control of plant diseases on the phylloplane. Annual Review. Phytopathology 20: 167-192.

Briton-Jones y E. Cheesman. 1931. Witch-broom control. Tropical Agriculture. Trinidad 8: 79-89.

Dabydeen, S. y T. N. Sreenivasan. 1989. Occurrece, Anatomy and Morphology of "Blisters" on cocoa seedling inoculated with Crinipellis perniciosa. Plant Disease 73: 481-484.

De Verteuil, J. 1932. Report of Agronomist. En Trinidad and Tobago. Departament Agriculture Administration Reporter 1931: 29-40.

Garcés, C. 1946. La escoba de bruja del cacao. Revista Facultad Nacional de Agronomía 4(24): 329-369.

INIAP (Instituto Nacional Autónomo de Investigaciones Agropecuarias, Ec). 1987. Manual del cultivo de cacao, Ecuador, $73 \mathrm{pp}$.

INIAP (Instituto Nacional Autónomo de Investigaciones Agropecuarias, Ec). 2008. Reconocimiento y manejo de enfermedades en cacao. Boletín divulgativo $\mathrm{N}^{\circ} 335.4-16 \mathrm{p}$.

Kilaru, A. y K. Hasenstein. 2005. Development and Pathogenicity of the fungus Crinipellis perniciosa on interaction with cacao leves. Biochemisty and Cell Biology 95(1): 101-107.
Macagnan, D., R. Romeiro, J. de Souza, y A. Pomella. 2006. Islation of Astinomycotes and Endospore-forming bacteria from the cacao-pod surface and their Antagonistic activity against the witches' broom and Black Pod pathogens. Phytoparasitica 24(2): 122-132.

Marelli, J.P., S. Maximova, K. Gramacho, S. Kang y M. Guiltinan. 2009. Infection biology of Moniliophthora perniciosa on Theobroma cacao and Alternate Solanaceous. Tropical Plant Biology 2: 149-160.

Rorer, J. 1913. The Suriname with-broom disease of cacao. Trinidad and Tobago, Dep. Agr. Circ. 10:1-13.

Scarpari, L.M., L.W. Meinhardt, P. Mazzafera, A. Pomella, M. Schiavinato, J. Cascardo, y G. Pereira. 2005. Biochemical changes during the development of witche' broom: the most important disease of cocoa in Brazil caused by Crinipellis perniciosa. Journal of Experimental Botany 56(413): 865-877.

Stahel, G. 1932. Contribution to the knowledge of wichbroom disease. Tropical Agriculture. Trinidad 9: 167-176.

Stell, F. 1929. Witch broom disease of cacao and its control. Research Review Apple Mycology 8: 160.

Stell, F. 1932. Witch-broom disease of cacao. Apple Mycology 11: 433.

Stell, F. 1938. Report of Plant Pathologist. 1937. Trinidad and Tobago. Department Agriculture. Admiration. 65:70.

Suarez, C. 1996. Control de enfermedades de cacao en un sistema sostenible de producción agrícola en el litoral ecuatoriano. Revista Informativa del INIAP 7: 8-11.

van Hall C.J. y A.W. Drost. 1907. Les balâis de sorcière du cacaoyer provoqués par Colletotrichum luxificum n. sp. Recueil des Travaux Botaniques Néerlandais 4: 243-321.

Wardlaw, C. 1929. Witch-broom in Surineme. Tropical Agriculture. Trinidad 6: 348-349.

Para citar este artículo: Rivera-Fernández, R. D., O. Valerezo-Beltron, L. Veras-Macías, J. E. Chavarría-Párraga y A. M. Guzmán-Cedeño. 2014. Efecto de la Poda fitosanitaria sobre la enfermedad escoba de bruja en el cultivo de Cacao. Revista Intropica Vol. 9: 129 - 136 